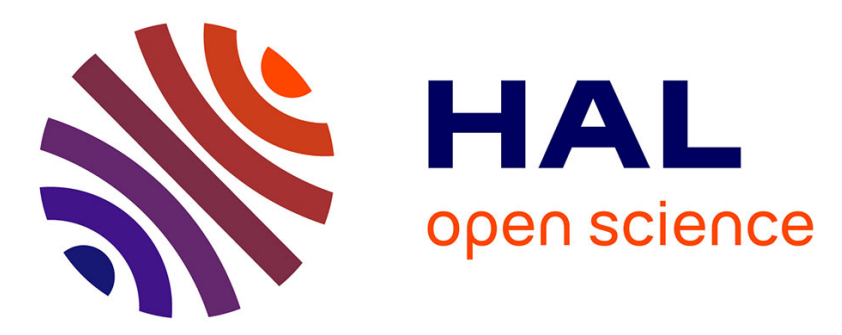

\title{
Unusual organisation, complexity and redundancy at the Escherichia coli hcp-hcr operon promoter
}

\author{
David L. Chismon, Douglas F Browning, Gregory K. Farrant, Stephen J.W.
} Busby

\section{> To cite this version:}

David L. Chismon, Douglas F Browning, Gregory K. Farrant, Stephen J.W. Busby. Unusual organisation, complexity and redundancy at the Escherichia coli hcp-hcr operon promoter. Biochemical Journal, 2010, 430 (1), pp.61-68. 10.1042/BJ20100623 . hal-00506524

\section{HAL Id: hal-00506524 \\ https://hal.science/hal-00506524}

Submitted on 28 Jul 2010

HAL is a multi-disciplinary open access archive for the deposit and dissemination of scientific research documents, whether they are published or not. The documents may come from teaching and research institutions in France or abroad, or from public or private research centers.
L'archive ouverte pluridisciplinaire HAL, est destinée au dépôt et à la diffusion de documents scientifiques de niveau recherche, publiés ou non, émanant des établissements d'enseignement et de recherche français ou étrangers, des laboratoires publics ou privés. 


\title{
Unusual organisation, complexity and redundancy at the Escherichia coli hcp-hcr operon promoter
}

\author{
David L. Chismon, Douglas F. Browning, \\ Gregory K. Farrant and Stephen J.W. Busby*
}

School of Biosciences, University of Birmingham, Edgbaston, Birmingham B15 2TT, UK

*To whom correspondence should be addressed s.j.w.busby@bham.ac.uk +44 (0)1214145439

Keywords: Escherichia coli, promoters, NarL, NsrR, nitrate, nitrite, reactive nitrogen species

Running title: E. coli hcp-hcr operon promoter 


\begin{abstract}
Expression from the Escherichia coli hcp-hcr operon promoter is optimally induced during anaerobic conditions in the presence of nitrite. This expression depends on transcription activation by FNR, which binds to a target centred at position -72.5 upstream of the transcript start site. Mutational analysis was exploited to identify the corresponding -10 and -35 hexamer elements. A DNA site for NarL and NarP, located at position -104.5, plays only a minor role, whilst NsrR binding to a DNA target centred at position +6 plays a major role in induction of the $h c p-h c r$ operon promoter. Electromobility shift assays show that NsrR binds to this target. The consequences of this for the kinetics of induction of the hcp-hcr operon are discussed.
\end{abstract}

\title{
INTRODUCTION
}

The expression of many E. coli transcripts is tightly controlled in response to environmental cues, and, in many instances, this control is exercised at the level of the promoter by the regulation of the initiation of transcript formation [1]. Two very important signals are the absence of oxygen and the presence of nitrate or nitrite ions, and many promoters are activated only when these are combined [2]. These signals are 'transmitted' to promoters by transcription factors that can either activate or repress transcription initiation [3]. Hence, absence of oxygen triggers the activity of FNR, a well-characterised transcription factor that is the master regulator of $E$. coli adaptation to growth in anaerobic conditions [4]. FNR binds to $\sim 25$ base pair sequences at target promoters and recruits RNA polymerase, thereby activating transcription. Similarly, the presence of nitrate or nitrite ions leads to the activation of NarL and its homologue, NarP, that belong to the response regulator family of transcription factors. Activation of both NarL and NarP is mediated by the membrane-bound NarX and NarQ sensor kinases that are triggered by nitrate or nitrite ions in the environment (reviewed in [5,6]). Upon activation, NarL and NarP bind to identical heptamer sequences and, at many target promoters, two heptamers are found as a 'tailto-tail' inverted repeat (often referred to as the 7-2-7 arrangement). These heptamers are found at a variety of locations at different target promoters and NarL and NarP have been found to modulate transcription by a variety of mechanisms. Many of these target promoters control the expression of gene products involved in the reduction of nitrate or nitrite and, hence, NarL and NarP are thought to be the principal regulators of nitrate and nitrite metabolism. However, recently, another transcription factor, NsrR, has been found to play a role at some promoters that are controlled by oxygen and by nitrate or nitrite ions (reviewed in $[7,8]$ ). NsrR appears to bind to 23 base pair sequences at many target promoters and it functions as a repressor [9]. The activity of NsrR is regulated by nitric oxide or reactive nitrogen species that convert NsrR to a form that is unable to bind to its targets and hence unable to repress transcription. Recall that nitric oxide and reactive nitrogen species are produced as by-products of nitrate and nitrite metabolism, and hence, nitrate- or nitrite-induced changes in transcription can be mediated by NsrR as well as by NarL and NarP.

The E. coli hcp-hcr operon encodes an iron-sulphur cluster containing protein (hcp is locus b0873 in cmr.jcvi.org) and an NADH oxidoreductase (hcr is locus b0872 in cmr.jcvi.org). The in vivo function of these proteins is not clear, but it is well established that their expression is induced by the absence of oxygen and the presence of nitrate or nitrite ions $[10,11]$. Studies of the $h c p-h c r$ operon regulatory region have identified a single promoter and mapped the transcript start [10]. Expression from this promoter was shown to be completely dependent on FNR, and a single DNA site for FNR, centred at position -72.5 (i.e. between base pairs 72 and 73 upstream of the transcript start) was identified [10]. An upstream 7-2-7 NarL/NarP-binding site at position -104.5 was also identified and it was suggested that this site is essential for stimulation of $h c p-h c r$ operon expression by nitrate or nitrite ions [11]. However, recent studies also found a 23 base pair DNA site for NsrR centred at position +6 , and showed that the $h c p-h c r$ promoter can be repressed by NsrR $[9,11]$. Hence, the major aim of this study was to quantify the relative contributions of NarL/NarP and NsrR to the regulation of the $h c p-h c r$ promoter by nitrate and nitrite ions. A second aim was to confirm the location of the DNA site for FNR at position -72.5 and to identify other functional determinants. To achieve these aims, we performed a mutational and deletion analysis of the $h c p-h c r$ operon promoter, and we report here that NsrR plays a major role whilst the effects of NarL and NarP are minimal. 


\section{EXPERIMENTAL}

\section{Bacterial strains, plasmids, promoter fragments and primers}

The bacterial strains, plasmids, promoter fragments and oligodeoxynucleotide primers used in this work are listed in Table 1. E. coli K-12 strain JCB387 and derivatives were used throughout this work. Strains JCB387 $\Delta n s r R$ and JCB38849S $\Delta n s r R$ were constructed by P1 transduction of the $\Delta n s r R$ mutation from strain JCB5010 [11].

The low-copy number lac expression vector, pRW50 [12], was used as the main cloning vector during this work and it was maintained in host cells using media supplemented with $35 \mu \mathrm{g} \cdot \mathrm{ml}^{-1}$ tetracycline. Plasmids pNF383, pSTBlue-1 and pGIT9 were maintained in host cells using media supplemented with $80 \mu \mathrm{g} \cdot \mathrm{ml}^{-1}$ ampicillin.

All the promoter fragments used on this work carry an upstream EcoRI site and a downstream HindIII site and were cloned into pRW50. By convention, positions at the hcp-hcr operon promoter are labelled with the reported transcript start point [10] designated as +1 and upstream and downstream locations prefixed with '-' and '+' respectively.

The hcp383-1, hcp383-2 and hcp383-3 fragments, which encode hcp-hcr promoter sequences from positions $-125,-92$ and -54 respectively, to position +98 , were constructed by PCR. DNA fragments were amplified using primers D10527 and either hcp-1 FWD, hcp-2 FWD or hcp-3 FWD using pNF383 as template. PCR products were restricted with EcoRI and HindIII and cloned into pRW50. Different mutations were generated in these fragments using different PCR methods.

Single base substitutions in promoter fragments are denoted $N X$, where $N$ is the position of the substitution relative to the transcript start, and $X$ is the substituted base in the non-template strand of the promoter. The hcp383-1n fragment, containing the $+9 \mathrm{G}$ and $+10 \mathrm{G}$ substitutions, was constructed by two step megaprimer PCR [13]. In the first step, a megaprimer was generated by PCR using primers hcp-n FWD and D10527 with hcp383-1 cloned in pRW50 as template. Purified megaprimer product was then used in a second PCR, together with primer D10520 and the same template. This generated the hcp383-1n fragment which was then cloned into pRW50. This recombinant plasmid was then used as a template in a further PCR to generate the hcp383-1ns fragment using hcp-s REV and D10520 as primers. Further point mutations were introduced into the hcp383-1ns fragment by megaprimer PCR using the hcp P9V FWD, hcp P13G FWD, hcp P14V FWD, hcp P35R FWD, and hcp P37V FWD primers.

The hcp383-3s fragment was constructed by PCR using primers D10520 and hcp-s REV using pRW50 carrying hcp383-3 as template. The hcp383-3ns fragment was constructed by PCR using primers hcp-3 FWD and hcp-s REV with pRW50 carrying hcp383-1ns as template.

\section{Promoter activity assays}

The pRW50 lac expression vector plasmid was exploited to measure the activity of cloned promoters. Hence, relevant $\Delta l a c$ strains were transformed with plasmids encoding either $h c p$-hcr operon promoter::lacZ or ogt promoter::lacZ fusions and $\beta$-galactosidase activities were measured using the Miller method [14]. Cells were grown in minimal medium (minimal salts with $0.4 \%$ glycerol, $10 \%$ Lennox broth, $40 \mathrm{mM}$ fumarate [15]) at $37^{\circ} \mathrm{C}$. For aerobic growth, cells were shaken vigorously, whilst, for anaerobic growth, they were held static in growth tubes $(150 \mathrm{~mm}$ long and $15 \mathrm{~mm}$ in diameter). Aerobic cultures were grown to an $\mathrm{OD}_{650}$ of 0.2 to 0.3 , anaerobic cultures were grown to an $\mathrm{OD}_{650}$ of 0.4 to 0.6 and assayed exactly as described previously [16]. Note that aerobically grown cells were harvested at a lower cell density when it is known that cultures are fully oxygenated. Throughout this study, secondary effects due to differences in metabolism between different culture conditions were minimised by comparing $\beta$-galactosidase expression controlled by different derivatives of the $h c p$-hcr operon promoter. $\beta$-galactosidase activities are reported as nmol of ONPG hydrolysed in our assay conditions $\mathrm{min}^{-1} \mathrm{mg}^{-1}$ dry cell mass and each activity is the average of three independent determinations.

\section{In vitro experiments}


DNase I footprinting of FNR at the $h c p-h c r$ operon promoter region was performed as in Browning et al. [16], using purified Ala-154 FNR and purified Aatll-HindIII hcp383-1 fragment that had been ${ }^{32}$ P-end labelled at the HindlII site using polynucleotide kinase and $\left[\gamma^{32}{ }^{32}\right]-A T P$.

Electromobility shift assays (EMSA) using crude protein extracts containing NsrR were run as in Browning et al. [17]. Extracts were made from a $\Delta n s r R$ derivative of JCB387 carrying either pGIT9, which expresses NsrR, or empty vector pSTBlue-1. Cells were grown anaerobically at $37^{\circ} \mathrm{C}$ in $50 \mathrm{ml}$ of minimum medium to $\mathrm{OD}_{650}=0.6$. Each culture was centrifuged in an Eppendorf $5810 \mathrm{R}$ centrifuge at $3000 \times \mathrm{g}$ for 15 minutes at $4^{\circ} \mathrm{C}$ and the pellet was resuspended in $5 \mathrm{ml}$ of ice cold wash buffer $(20 \mathrm{mM}$ Tris- $\mathrm{HCl}(\mathrm{pH} 8.0), 5 \%$ glycerol, $1 \mathrm{mM} \mathrm{DTT}, 200 \mu \mathrm{g} \cdot \mathrm{ml}^{-1}$ phenylmethylsulfonyl fluoride and $4 \mu \mathrm{g} \cdot \mathrm{ml}^{-1}$ pepstatin). Suspensions were recentrifuged and pellets were resuspended in $2 \mathrm{ml}$ of wash buffer. Cells were disrupted by sonication using a Misonix Ultrasonic Processor XL for three 20 second bursts with 30 seconds cooling between each sonication step. Cell debris was removed by centrifuging $1 \mathrm{ml}$ samples in an Eppendorf $5417 \mathrm{R}$ centrifuge at $20800 \mathrm{xg}$ for 30 minutes at $4^{\circ} \mathrm{C}$. Cell lysates were stored at $4^{\circ} \mathrm{C}$ and used within in 24 hours of preparation.

For the EMSA assays, purified EcoRI-HindIII hcp383-3s and hcp383-3ns promoter fragments were ${ }^{32} \mathrm{P}$-end labelled using polynucleotide kinase and $\left[\gamma_{-}{ }^{32} \mathrm{P}\right]-\mathrm{ATP}$. Approximately $0.5 \mathrm{ng}$ of each fragment was incubated with varying amounts of lysate ( 0 to $9 \mu \mathrm{g}$ of protein) in buffer containing $10 \mathrm{mM}$ potassium phosphate ( $\mathrm{pH} 7.5$ ), $100 \mathrm{mM}$ potassium glutamate, $1 \mathrm{mM}$ EDTA, $50 \mu \mathrm{M} \mathrm{DTT}, 5 \%$ glycerol and $25 \mu \mathrm{g} . \mathrm{ml}^{-1}$ herring sperm DNA. The final reaction volume was $10 \mu \mathrm{l}$. After incubation at $37^{\circ} \mathrm{C}$ for 20 minutes, samples were run in $0.25 \times$ TBE on a $6 \%$ polyacrylamide gel containing $2 \%$ glycerol at $12 \mathrm{~V} . \mathrm{cm}^{-1}$ and analysed using a Bio-Rad Molecular Imager FX and Quantity One software (Bio-Rad).

\section{RESULTS}

\section{Analysis of the hcp-hcr operon promoter}

The hcp383-1 EcoRI-HindIII DNA fragment, illustrated in Figure 1, covers the hcp-hcr operon regulatory region that includes the $h c p-h c r$ promoter. The figure shows the base sequence from position -125 to position +98 with respect to the reported transcript start, and the previously proposed DNA sites for NarL and NarP, for FNR and for NsrR [9-11]. Note that the sequence 5'-TCTGCGTAA-3' from position -121 to position -113 corresponds to the last three codons of the preceding gene, ybjE (locus b0874 in cmr.jcvi.org) and thus the hcp383-1 DNA fragment contains the complete ybjE-hcp intergenic region and is likely to carry all the sequence elements needed for hcp-hcr promoter activity and regulation. Furthermore, extension of the hcp383-1 DNA fragment to position -285 to position +98 with respect to the $h c p-h c r$ transcript start had no measurable effects in the assays described below (unpublished results).

In order to assess the importance of different elements for the activity of the $h c p-h c r$ operon promoter, the hcp383-1 fragment was cloned into plasmid pRW50, a low copy number lac expression vector, and this fuses the promoter to the lacZ gene that encodes $\beta$-galactosidase. E. coli K-12 strain JCB387 containing the recombinant plasmid gives rise to $\mathrm{Lac}^{+}$red colonies during growth on Maconkey indicator plates. In contrast, with empty pRW50, Lac ${ }^{-}$white colonies are observed, since the JCB387 chromosome carries a deletion of the lac operon.

In a preliminary experiment to identify sequence elements essential for the hcp-hcr operon promoter, error prone PCR was used to generate several independent preparations of EcoRI-HindIII promoter fragment carrying random point mutations. The fragments were then cloned into pRW50, the mixture of resulting recombinant plasmids was transformed into E. coli strain JCB387, and transformants were grown on Maconkey indicator plates. As expected, the majority of colonies scored as $\mathrm{Lac}^{+}$, but, after screening over 500 transformants, we identified $7 \mathrm{Lac}^{-}$colonies. Sequence analysis showed that each of these colonies contained pRW50 carrying the $h c p-h c r$ operon promoter fragment with different mutations. Three of the recombinant plasmids carried a point mutation at position -67 of the $h c p-h c r$ promoter, two carried a mutation at position -69 , one carried a mutation at position -78 , and one carried a mutation at position -36. The different mutations are shown in Figure 1. Strikingly, six out of seven of 
these changes fall in the proposed DNA site for FNR and would be expected to reduce FNR binding at this target. This is consistent with FNR being essential for expression from the hcp-hcr operon promoter. DNase I footprinting was then used to provide a biochemical assay to confirm FNR binding at the proposed DNA site, and the result presented in Figure 2 shows that purified FNR creates a clear single $\sim 25$ base pair footprint covering the target centred at position -72.5.

Surprisingly, none of the 'down' mutations identified in the preliminary analysis fell in the upstream DNA site for NarL and NarP. Since this target was thought to be important for promoter activity [10,11], we constructed two derivatives of the hcp383-1 fragment, hcp383-2 and hcp383-3, to investigate directly the role of the DNA site for NarL and NarP. The hcp383-2 fragment carries a deletion that removed just this site whilst, in the hcp383-3 fragment, both the DNA site for FNR and the DNA site for NarL and NarP are deleted (Figure 1). The upper panel of Figure 3 illustrates measurements of $\beta$-galactosidase activity in JCB387 cells containing pRW50 carrying the hcp383-1, hcp383-2 or hcp383-3 fragments, grown in different conditions. The data show that, with hcp383-1, hcp-hcr operon promoter expression, as measured by $\beta$-galactosidase expression, is induced by anaerobiosis. Some further induction is found with added sodium nitrate, whilst added sodium nitrite results in optimal induction. Removal of the DNA site for NarL and NarP in the hcp383-2 fragment causes a decrease in nitrate-dependent induction whilst having a minimal effect on the greater nitrite-dependent induction. In contrast, as expected, removal of the DNA site for FNR in the hcp383-3 fragment prevented all induction.

In a complementary experiment, we constructed derivatives of the hcp383-1 fragment carrying point mutations in the proposed DNA site for NarL and NarP (hcp383-101) or in the DNA site for FNR (hcp383-102). The lower panel of Figure 3 illustrates measurements of $\beta$-galactosidase activity in JCB387 cells containing pRW50 carrying the hcp383-1, hcp383-101 or hcp383-102 fragments. The data underscore the importance of FNR for induction of the hcp-hcr operon promoter and corroborate the deletion analysis.

\section{Effects of NsrR at the hcp-hcr promoter}

The data presented in Figure 3 argue that NarL and NarP play but a small role in the induction of the $h c p-h c r$ promoter. To quantify effects due to NsrR, a derivative of the hcp383-1 fragment, carrying substitutions at positions +9 and +10 , in the suggested DNA site for NsrR was constructed (see Figure 1). The resulting fragment, hcp383-1n was cloned into pRW50. The upper panel of Figure 4 illustrates measurements of $\beta$-galactosidase in JCB387 cells containing pRW50 carrying either the hcp383-1 or hcp383-1n fragment, grown in different conditions. The data show that, with the hcp383-1n fragment, promoter expression is increased in anaerobic conditions without the addition of nitrate or nitrite, and that induction by nitrate and nitrite is greatly decreased. These results argue that nitrate- and nitritedependent induction of the $h c p-h c r$ promoter is principally due to relief of repression by NsrR. This conclusion was confirmed by comparison of the activity of the hcp-hcr promoter, carried by the hcp383-1 fragment, in an $n s r R^{+}$and a $\Delta n s r R$ background. In the $\Delta n s r R$ background, full induction is observed in anaerobic conditions without the addition of nitrate or nitrite (Figure 4).

Figure 5 illustrates an EMSA to measure the binding of NsrR to the $h c p-h c r$ promoter region. In this experiment, a shorter derivative of the hcp383-3 fragment, hcp383-3s, carrying hcp-hcr promoter sequences from positions -54 to +46 , was end-labelled with ${ }^{32} \mathrm{P}$ and incubated with cell extracts from $\Delta n s r R$ cells that carried either a plasmid encoding NsrR or a control empty vector plasmid. DNA-protein complexes were separated using polyacrylamide electrophoresis. With extracts containing NsrR, the EMSA shows a unique NsrR-DNA complex, but this complex is absent with the control extract. Furthermore, the formation of the complex was greatly decreased when the fragment carried the substitutions at positions +9 and +10 , in the DNA site for NsrR. Note that the residual binding of NsrR to the mutated DNA site likely accounts for the small NsrR-dependent nitrite-dependent induction of the $h c p-h c r$ promoter seen with the hcp383-1n fragment (Figure 4).

\section{Identification of -10 and -35 elements at the hcp-hcr operon promoter}

It is well established that the two principal sequence elements required for the activity of most bacterial promoters are the -10 and -35 hexamers that interact with the RNA polymerase $\sigma$ subunit [1]. Inspection of the base sequence upstream of the $h c p-h c r$ promoter transcript start suggested that the promoter -10 
hexamer element is 5'-TAACCT-3', corresponding to the consensus 5'-TATAAT-3' at $3 / 6$ positions. If this were the case, the likely corresponding -35 hexamer element would be 5'-TTTTAT-3' (Figure 1). Although this corresponds to the 5'-TTGACA-3' consensus at only 2/6 positions, it is consistent with the observation that one of the seven 'down' mutations in the hcp-hcr operon promoter, identified after random mutagenesis using error-prone PCR, fell at position -36, changing 5'-TTTTAT-3' to 5'-TCTTAT-3' (Figure 1). In order to confirm our assignment of the two hexamer elements, we used site-directed mutagenesis to make changes in each hexamer and then measured the effects of the different changes. For this experiment, we used the shorter hcp383-1ns fragment which carries the hcp-hcr promoter sequence from position -125 to position +46 and the substitutions at positions +9 and +10 , in the DNA site for NsrR. Derivatives of the hcp383-1ns fragment carrying different mutations were cloned into pRW50, recombinant plasmids were transformed into strain JCB387 and the activity of the $h c p-h c r$ promoter was deduced from measurements of $\beta$-galactosidase activities. Results in Table 2 show that mutations at positions $-14,-13$ and -9 , that changed the putative -10 hexamer away from the consensus, all caused substantial decreases in promoter activity. Similarly, substitutions at positions -37 and -36 that altered the -35 hexamer element away from the consensus, also caused decreases. A substitution at position -35 that changed the hexamer to 5'-TTGTAT-3', which accords better with the consensus, led to an increase in activity. Taken together, these data support the assignation of 5'-TAACCT-3' and 5'-TTTTAT-3' as the hcp-hcr operon promoter -10 and -35 hexamer elements respectively.

\section{Kinetics of activation of promoters in response to nitrate}

The induction of promoter activity by NarL/NarP follows from the direct sensing of external nitrate or nitrite ions by the NarX/NarQ transmembrane sensor kinases [5,6]. In contrast, the induction of a promoter that is repressed by NsrR in response to nitrate or nitrite ions depends on the build up of either nitric oxide or other reactive nitrogen species that result from the metabolism of nitrate or nitrite $[7,8]$. We reasoned that, upon addition of nitrate ions to a culture of $E$. coli, induction that was dependent on NarL/NarP would be more rapid than induction that was mainly dependent on NsrR. To test this, we compared the kinetics of induction of the $h c p-h c r$ promoter by a pulse of sodium nitrate with the induction of the ogt promoter, which is known to be directly activated solely by NarL [18]. Figure 6 shows the results of this experiment using the pRW50 lac expression vector carrying either the hcp383-1 promoter fragment or the ogt100 fragment that carries the ogt promoter. The data show a clear lag in the induction of the hcp-hcr operon promoter in response to nitrate compared to the ogt promoter.

\section{DISCUSSION}

Many E. coli transcription factors interact at more than one promoter, and most promoter targets are regulated by more than one transcription factor [3]. This results in a complex transcriptional regulatory network that permits responses to different combinations of environmental inputs [19]. The promoter of the E. coli hcp-hcr operon is activated by two signals, anaerobiosis and nitrate or nitrite ions, which are mediated by two different transcription factors $[2,10,11]$. Hence this promoter is completely dependent on FNR, the principal regulator of anaerobic adaptation, which binds to a location centred at position -72.5 [10]. This location is unusual, since the DNA site for FNR is centred near position -41.5 at the vast majority of FNR-dependent promoters [20], but the biological significance, if any, is unclear. Concerning the mechanism of activation, the consequence of the unusual location is that activation must be mediated by an interaction between FNR and the RNA polymerase $\alpha$ subunit, rather than an interaction between FNR and the RNA polymerase $\sigma$ subunit, as at the majority of FNR-dependent promoters [20]. This is because the RNA polymerase $\alpha$ subunit contains a flexible linker that permits contact with upstream-bound transcription factors, whilst the RNA polymerase $\sigma$ factor can only interact directly to transcription factors that overlap the promoter -35 element [1].

The second functional transcription factor at the $h c p-h c r$ operon is the NsrR repressor whose activity is modulated by some of the by-products of nitrate and nitrite metabolism $[7,8]$. The consequence of this is a lag in the induction of the $h c p-h c r$ transcript in response to increases in nitrate, compared to transcripts whose induction is directly stimulated by nitrate. Again, the biological significance of this is unknown, and the situation is not helped by our lack of understanding of the function of the $h c p$ and $h c r$ gene products. Since their most likely function is some role in detoxification of reactive nitrogen species, it is not difficult 
to rationalise the involvement of NsrR, which controls a network of gene products concerned with managing nitric oxide and other reactive nitrogen species.

Previous studies of the E. coli hcp-hcr operon promoter have focussed on possible roles for NarL and the DNA site for NarL and NarP located at position -104.5, and confirmed that purified NarL can bind to this site $[10,11]$. However, our results show that this site plays but a small role in the induction of the $h c p-$ hcr operon promoter. We surmise that the previously reported lack of induction in narL mutants [10] was due to a failure to stop NsrR-dependent repression because of reduced nitrate and nitrite metabolism, rather than due to the absence of direct NarL-mediated effects. The apparent secondary role for the upstream DNA site for NarL and NarP at the $h c p-h c r$ promoter is best explained as a vestige of evolution, though it is possible that the site either plays another role or comes into play in conditions that are yet to be discovered. In any case, it is now clear that binding to some targets by some $E$. coli transcription factors has no apparent effect on promoter activity. For example, in the case of the cyclic AMP receptor protein, up to $25 \%$ of hundreds of binding sites are likely to be redundant [21,22], whilst, for RutR, the majority of its 20 characterised binding targets play no role in controlling promoter activity [23]. The simplest explanation for this is that evolution drives the creation of new sites that are then eliminated if they have no function, and that genomes are bound to contain redundant sites that are 'awaiting' elimination. In the case of NarL, bioinformatics predicts over 300 binding targets throughout the E. coli chromosome [24] but transcriptomic experiments argue that NarL likely controls no more than 100 promoters directly [2]. Following analysis by chromatin immunoprecipitation several bona fide DNA sites for NarL that played little or no role in transcriptional regulation were identified [25]. We suggest that the upstream DNA site for NarL and NarP at the E. coli K-12 hcp-hcr promoter may also be moving towards redundancy. Consistent with this, comparison of the promoter sequence in several related bacteria show that core elements, including the DNA sites for FNR and NsrR, are better conserved than the upstream flanking sequences that contain the DNA site for NarL and NarP (Figure 7).

\section{ACKNOWLEDGEMENTS}

We thank the Wellcome Trust for funding this work with a programme grant and the UK BBSRC for a studentship for DLC. We are grateful to Jeff Cole for helpful discussions and unfailing support throughout the project.

\section{REFERENCES}

1. Browning, D. and Busby, S. (2004) The regulation of bacterial transcription initiation. Nature Rev. Microbiol. 2, 57-65

2. Constantinidou, C., Hobman, J.L., Griffiths, L., Patel, M.D., Penn, C.W., Cole, J.A. and Overton, T.W. (2006) A reassessment of the FNR regulon and transcriptomic analysis of the effects of nitrate, nitrite, NarXL, and NarQP as Escherichia coli K12 adapts from aerobic to anaerobic growth. J. Biol. Chem. 281, 4802-4815

3. Salgado, H., Santos-Zavaleta, A., Garma-Castro, S., Peralto-Gil, M., Penaloza-Spinola, M.I., Martinez-Antonio, A., Karp, P.D. and Collado-Vides, J. (2006) The comprehensive updated regulatory network of Escherichia coli K-12. BMC Bioinformatics doi:10.1186/1471-2105-7-5

4. Spiro, S. and Guest, J.R. (1990) FNR and its role in oxygen-regulated gene expression in Escherichia coli. FEMS Microbiol. Rev. 6, 399-428

5. Darwin, A.J. and Stewart, V. (1996) The NAR modulon systems: nitrate and nitrite regulation of anaerobic gene expression. In Regulation of gene expression in Escherichia coli (Lin, E. and Lynch, A., eds) pp 343-359, R.G. Landes Company, Austin, TX

6. Stewart V. (2003) Nitrate- and nitrite-responsive sensors NarX and NarQ of proteobacteria. Biochem. Soc. Trans. 31,1-10

7. Spiro, S. (2007) Regulators of bacterial responses to nitric oxide. FEMS Microbiol. Rev. 31,193211 
8. Tucker, N.P., Le Brun, N.E., Dixon, R. and Hutchings, M.I. (2010) Theres's NO stopping NsrR, a global regulator of the bacterial NO stress response. Trends Microbiol. 18,149-156

9. Partridge, J.D., Bodenmiller, D.M., Humphrys, M.S. and Spiro, S. (2009) NsrR targets in the Escherichia coli genome: new insights into DNA sequence requirements for binding and a role for NsrR in the regulation of motility. Mol. Microbiol. 73, 680-694

10. Filenko, N.A., Browning, D.F. and Cole, J.A. (2005) Transcriptional regulation of a hybrid cluster (prismane) protein. Biochem. Soc. Trans. 33, 195-197

11. Filenko, N., Spiro, S., Browning, D.F., Squire, D., Overton, T.W., Cole, J. and Constantinidou, C. (2007) The NsrR regulon of Escherichia coli K-12 includes genes encoding the hybrid cluster protein and the periplasmic, respiratory nitrite reductase. J. Bacteriol. 189, 4410-4417

12. Lodge, J., Fear, J., Busby, S., Gunasekaran, P. and Kamini, N-R. (1992) Broad host range plasmids carrying the Escherichia coli lactose and galactose operons. FEMS Microbiol. Lett. 95, 271-276

13. Sarkar, G. and Sommer S.S. (1990) The 'megaprimer' method of site directed mutagenesis. Biotechniques 8, 404-407

14. Miller, J. (1972) Experiments in Molecular Genetics. Cold Spring Harbor, NY; Cold Spring Harbor Laboratory Press.

15. Pope, N.R. and Cole, J. (1982) Generation of a membrane potential by one of two independent pathways of nitrite reduction by E. coli. J. Gen. Microbiol. 128, 319-322

16. Browning, D.F., Cole, J.A. and Busby, S.J.W. (2004) Transcription activation by remodelling of a nucleoprotein assembly: the role of NarL at the FNR-dependent Escherichia coli nir promoter. Mol. Microbiol. 53, 203-215

17. Browning, D.F., Lee, D.J., Spiro, S. and Busby, S.J. (2010) Down-regulation of the Escherichia coli K-12 nrf promoter by binding of the NsrR nitric oxide sensing transcription repressor to an upstream site. J. Bacteriol. In press (epub ahead of print, doi:10.1128/JB.00218-10)

18. Squire, D.J., Xu, M., Cole, J.A., Busby, S.J, and Browning, D.F. (2009) Competition between NarL-dependent activation and Fis-dependent repression controls expression from the Escherichia coli yeaR and ogt promoters. Biochem. J. 420, 249-257

19. Barnard, A., Wolfe, A. and Busby, S.J. (2004) Regulation at complex bacterial promoters: how bacteria use different promoter organisations to produce different regulatory outcomes. Current Opinion in Microbiology 7, 102-108

20. Browning, D.F., Lee, D.J., Green, J. and Busby, S.J. (2002) Secrets of bacterial transcription initiation taught by the Escherichia coli FNR protein, in "Signals, Switches, Regulons \& Cascades: Control of Bacterial Gene Expression" SGM Symposium vol 61, pp 127-142

21. Grainger, D.C., Hurd, D., Harrison, M., Holdstock, J. and Busby, S.J. (2005) Studies of the distribution of Escherichia coli CAMP receptor protein and RNA polymerase along the $E$. coli chromosome. Proc. Natl, Acad. Sci USA 102,17693-17698

22. Hollands, K., Busby, S.J. and Lloyd, G.S. (2007) New targets for the cyclic AMP receptor protein in the E. coli K-12 genome. FEMS Letters 274, 89-94

23. Shimada, T., Ishihama, A., Busby, S.J. and Grainger, D.C. (2008) The Escherichia coli RutR transcription factor binds at targets within genes as well as intergenic regions. Nucl. Acids Res. 36, 3950-3955

24. Robison, K., McGuire, A.M. and Church, G.M. (1998) A comprehensive library of DNA-binding site matrices for 55 proteins applied to the complete Escherichia coli K-12 genome. J. Mol. Biol. 284, 241-254

25. Xu, M. (2009) Genomic studies of the Escherichia coli NarL protein. Ph. D Thesis M0446099BU, University of Birmingham, U.K. 
26. Page, L., Griffiths, L. and Cole, J.A. (1990) Different physiological roles of two independent pathways for nitrite reduction to ammonia by enteric bacteria. Arch. Microbiol. 154, 349-354

27. Browning, D.F., Cole, J.A. and Busby, S.J. (2008) Regulation by nucleoid-associated proteins at the Escherichia coli nir operon promoter. J. Bacteriol. 190, 7258-7267

28. Bodenmiller, D.M. and Spiro, S. (2006) The yjeB (nsrR) gene of Escherichia coli encodes a nitric oxide-sensitive transcriptional repressor. J. Bacteriol. 188, 874-881

29. Chaudhuri, R.R. and Pallen, M.J. (2006) xBASE Nucl. Acids Res. 34, D335-D337, doi:10.1093/nar/gkj140 
Table 1: Bacterial strains, plasmids, promoter fragments and oligodeoxynucleotide primers

\begin{tabular}{|c|c|c|}
\hline Name & Details & Source \\
\hline \multicolumn{3}{|l|}{ Bacterial strains } \\
\hline JCB5010 & $\Delta / a c U 169$ araD139 rpsL gyrA $\triangle n s r R$ & Filenko et al. [11] \\
\hline JCB387 & $\Delta$ nir $\Delta / a c$ & et al. [26] \\
\hline JCB387 $\Delta n s r R$ & $\Delta n s r R$ derivative & This work \\
\hline JCB38849S & $\begin{array}{l}\text { Tet }^{\mathrm{s}} \text { version of JCB387 narL narP253::Tn10dCm } \\
\Delta \text { himA452::Tn10dTc isolated as a fusaric acid resistant } \\
\text { colony }\end{array}$ & Browning et al. [27] \\
\hline JCB38849S $\Delta n s r R$ & $\Delta n s r R$ derivative & This work \\
\hline \multicolumn{3}{|l|}{ Bacterial plasmids } \\
\hline pRW50 & $\begin{array}{l}\text { Broad host range lacZ fusion vector for cloning promoters } \\
\text { on EcoRI-Hindlll fragments: contains the RK2 origin of } \\
\text { replication and encodes } T c^{R}\end{array}$ & Lodge et al. [12] \\
\hline pNF383 & $\begin{array}{l}\text { pAA182 containing extended E. coli hcp-hcr promoter } \\
\text { region on an EcoRI-HindllI fragment }\end{array}$ & Filenko et al. [10] \\
\hline pSTBlue-1 & Cloning vector containing the pUC origin of replication. & Novagen \\
\hline pGIT9 & pSTBlue-1 containing E. coli nsrR & $\begin{array}{l}\text { Bodenmiller } \\
\text { and Spiro [28] }\end{array}$ \\
\hline \multicolumn{3}{|c|}{ Promoter fragments (all EcoRI-HindIII fragments) } \\
\hline hср383-1 & $\begin{array}{l}\text { E. coli hcp-hcr promoter fragment carrying } \\
\text { nucleotide sequences from }-125 \text { to }+98\end{array}$ & This work \\
\hline hсp383-2 & $\begin{array}{l}\text { E. coli hcp-hcr promoter fragment carrying } \\
\text { nucleotide sequences from }-92 \text { to }+98\end{array}$ & This work \\
\hline hcp383-3 & $\begin{array}{l}\text { E. coli hcp-hcr promoter fragment carrying } \\
\text { nucleotide sequences from }-54 \text { to }+98\end{array}$ & This work \\
\hline hcp383-1n & $\begin{array}{l}\text { Fragment hcp } 383-1 \text { carrying } A \text { to } G \text { and } T \text { to } G \text { mutations } \\
\text { at positions }+9 \text { and }+10\end{array}$ & This work \\
\hline hcp383-1ns & $\begin{array}{l}\text { hcp-hcr promoter fragment carrying nucleotide } \\
\text { sequences from }-125 \text { to }+46 \text { and carrying } A \text { to } G \text { and } T \text { to } \\
G \text { mutations at positions }+9 \text { and }+10\end{array}$ & This work \\
\hline hcp383-3s & $\begin{array}{l}h c p-h c r \text { promoter fragment carrying nucleotide } \\
\text { sequences from }-54 \text { to }+46\end{array}$ & This work \\
\hline hcp383-3ns & $\begin{array}{l}\text { Fragment hcp383-3s carrying } A \text { to } G \text { and } T \text { to } G \text { mutations } \\
\text { at positions }+9 \text { and }+10\end{array}$ & This work \\
\hline
\end{tabular}


ogt100

E. coli ogt promoter fragment carrying nucleotide sequences from -269 to +51

Squire et al. [18]

Oligodeoxynucleotide primers (all are shown 5' to 3')

D10520

D10527

CCCTGCGGTGCCCCTCAAG

hcp-1 FWD

hcp-2 FWD

hcp-3 FWD

GCAGGTCGTTGAACTGAGCCTGAAATTCAGG

hcp-n FWD

CCCGAATTCTTTCTCTGCGTAATACCTCTCTGGCGGT

CCCGAATTCCTGCCGCCAAAATTGCGCTAAATC

CCCGAATTCGTTGCATGAAAAATCCCTTTTATCC

hcp-s REV

CCTTAAACATGTATATTAAGGATAACTTTAAAAGG

hcp P9V FWD

CCCAAGCTTGCACACAAAACATGATCACACCTT

hcp P13G FWD

GCGTTAAGCGTCTTAACCVTAAACATGTATATTAA

hcp P14V FWD

GCGTTAAGCGTCTTGACCTTAAACATGTATATTAA

hcp P35R FWD

GCGTTAAGCGTCTVAACCTTAAACATGTATATTAA

hcp P37V FWD

GAAAAATCCCTTRTATCCCCGCGTTAAG

GAAAAATCCCVTTTATCCCCGCGTTAAG 
Table 2: Effects of point mutations in the hcp-hcr operon promoter -10 and -35 elements

\begin{tabular}{|c|c|c|c|c|}
\hline \multirow[b]{2}{*}{$\begin{array}{c}\text {-35 Element } \\
\text { (TTGACA) }\end{array}$} & & \multirow[b]{2}{*}{ Mutation } & \multicolumn{2}{|c|}{ Activity } \\
\hline & $\begin{array}{c}\text {-10 Element } \\
\text { (TATAAT) }\end{array}$ & & Aerobic & Anaerobic \\
\hline $\begin{array}{cc}\mathbf{- 3 7} & \mathbf{- 3 2} \\
\text { TTTTAT }\end{array}$ & $\begin{array}{cc}-14 & -9 \\
\text { TAACCT }\end{array}$ & none & 2.9 & 100.0 \\
\hline \multicolumn{5}{|c|}{ Mutations in the -10 element } \\
\hline TTTTAT & TAACCA & $-9 A$ & 0.4 & 6.2 \\
\hline TTTTAT & 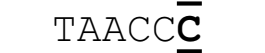 & $-9 C$ & 0.4 & 2.8 \\
\hline TTTTAT & TGACCT & $-13 G$ & 0.5 & 2.9 \\
\hline TTTTAT & $\underline{\bar{A} \bar{A}} \bar{A} C \mathrm{CT}$ & $-14 A$ & 0.2 & 15.0 \\
\hline TTTTAT & $\overline{\mathbf{G}} A A C C T$ & $-14 G$ & 0.4 & 3.6 \\
\hline TTTTAT & $\overline{\mathbf{C}} A A C C T$ & $-14 C$ & 0.4 & 8.7 \\
\hline \multicolumn{5}{|c|}{ Mutations in the -35 element } \\
\hline TTGTAT & TAACCT & $-35 G$ & & 246.0 \\
\hline тСТтАТ & TAACCT & $-36 C$ & 1.1 & 13.0 \\
\hline стTтTAт & TAACCT & $-37 C$ & 0.4 & 6.1 \\
\hline ӒтTTAт & TAACCT & $-37 A$ & 0.4 & 3.3 \\
\hline
\end{tabular}

$\beta$-galactosidase expression was measured in JCB387 cells carrying pRW50 containing the hcp383-1ns promoter fragment with single point mutations at different locations in the proposed -35 or -10 hexamer elements. The different base changes are shown in the first two columns and the consensus -35 and -10 hexamers for $E$. coli promoters are given at the head of each column. Cells were grown aerobically or anaerobically at $37^{\circ} \mathrm{C}$ in minimal medium. Each measurement is the average of three biological replicates and is expressed as a percentage of the measured $\beta$-galactosidase activity during anaerobic growth with the starting hcp383-1ns fragment. 


\section{FIGURE LEGENDS}

\section{Figure 1. Base sequence of the hcp383-1 promoter DNA fragment}

The hcp383-1 fragment carries the $h c p-h c r$ operon promoter sequence from position -125 to position +98 flanked by an upstream EcoRI site (boxed) and a downstream Hindlll site (boxed). The previously proposed DNA targets [11] for NarL (and NarP), FNR and NsrR are indicated by shaded horizontal inverted arrows. Consensus binding sequences are shown in bold above each target, aligned with the actual sequence, and the centre of the site is noted. In the consensus sequences, $Y$ denotes either $C$ or $\mathrm{T}, \mathrm{M}$ denotes $\mathrm{A}$ or $\mathrm{C}, \mathrm{K}$ denotes $\mathrm{G}$ or $\mathrm{T}, \mathrm{R}$ denotes $\mathrm{A}$ or $\mathrm{G}, \mathrm{W}$ denotes $\mathrm{A}$ or $\mathrm{T}$, and $\mathrm{N}$ denotes any base. The proposed promoter -35 and -10 hexamer elements are underlined and labelled. The reported transcription start site for the $h c p-h c r$ operon promoter [10] is identified with a bent arrow and the $h c p$ gene translation start codon (ATG) is in bold type. The upstream ends of the hcp383-2 and hcp383-3 fragments are indicated by solid lines that become dotted lines above the sequence. Base substitutions described in the text are indicted by vertical lines.

\section{Figure 2. Binding of FNR at the hcp-hcr promoter}

The figure shows a DNase I footprint of purified FNR binding at the $h c p$-hcr operon promoter. Endlabelled hcp383-1 Aatll-HindIII fragment was incubated with increasing concentrations of Ala154 FNR and subjected to DNase I footprint analysis. The concentration of FNR was: lane 1, no protein; lane 2, $0.5 \mu \mathrm{M}$; lane 3, $1.0 \mu \mathrm{M}$; lane 4, $2.0 \mu \mathrm{M}$; lane 5, 4.0 $\mu \mathrm{M}$. The gel was calibrated using a Maxam-Gilbert ' $G+A$ ' sequencing reaction and relevant positions are indicated. The location of the DNA site for FNR is shown by a box and hypersensitive sites due to FNR binding are starred.

\section{Figure 3. Regulation at the hcp-hcr promoter: effects of nested upstream deletions}

The upper panel shows a bar chart that illustrates $\beta$-galactosidase activities measured in JCB387 cells carrying pRW50, containing either the hcp383-1 fragment, the hcp383-2 fragment, or the hcp383-3 fragment. Cells were grown in minimal medium, aerobically or anaerobically at $37^{\circ} \mathrm{C}$, and, where indicated, a supplement of $20 \mathrm{mM}$ sodium nitrate or $2.5 \mathrm{mM}$ sodium nitrite was added. $\beta$-galactosidase activities are expressed as nmol of ONPG hydrolysed $\mathrm{min}^{-1} \mathrm{mg}^{-1}$ dry cell mass. Each activity is the average of three biological replicates and the error bars indicate the standard deviation of the replicates from the average. The lower panel shows a bar chart which illustrates an identical experiment that measured $\beta$-galactosidase activities in JCB387 cells carrying pRW50, containing either the hcp383-1 fragment, the hcp383-101 fragment, or the hcp383-102 fragment. The hcp383-101 fragment carries the $-110 \mathrm{G}$ and $-99 \mathrm{C}$ mutations in the proposed DNA site for NarL and NarP, and the hcp383-102 fragment carries the $-78 \mathrm{C}$ and $-67 \mathrm{G}$ mutations in the DNA site for FNR.

\section{Figure 4. Regulation at the hcp-hcr promoter: effects of NsrR}

The figure illustrates $\beta$-galactosidase activities measured in JCB387 cells (upper bar chart) or JCB387 $\Delta n s r R$ cells (lower bar chart) carrying pRW50, containing either the hcp383-1 fragment or the hcp383-1n fragment with the $+9 \mathrm{G}$ and $+10 \mathrm{G}$ mutations that abrogate NsrR binding. Cells were grown in minimal medium, anaerobically at $37^{\circ} \mathrm{C}$, and, where indicated, a supplement of $20 \mathrm{mM}$ sodium nitrate or $2.5 \mathrm{mM}$ sodium nitrite was added. $\beta$-galactosidase activities are expressed as nmol of ONPG hydrolysed $\mathrm{min}^{-1}$ $\mathrm{mg}^{-1}$ dry cell mass. Each activity is the average of three biological replicates and the error bars indicate the standard deviation of the replicates from the average.

\section{Figure 5. EMSA analysis of NsrR binding at hcp-hcr promoter}

The figure shows an autoradiogram from an EMSA performed with ${ }^{32} \mathrm{P}$-labelled hcp383-3s fragment (lanes 10-19) or the derivative hcp383-3ns fragment with the $+9 \mathrm{G}$ and $+10 \mathrm{G}$ mutations that abrogate NsrR binding (lanes 1-9). These fragments carry hcp-hcr operon promoter sequences from position -54 
to position +46 . Labelled fragments were incubated with increasing amounts of soluble cell extract from strain JCB38849S $\Delta n s r R$ carrying either pGIT9 which expresses NsrR (+NsrR; lanes 2-5,11-14), or empty vector pSTBlue-1 (-NsrR; lanes 7-9,16-19). The total amount of protein in the extract used in each reaction was: lanes $1,6,10$ and 15 , no protein; lanes 2, 7, 11 and $16,1.5 \mu$; lanes $3,8,12$ and 17,3 $\mu \mathrm{g}$; lanes 4, 9, 13 and 18, $6 \mu \mathrm{g}$; lanes 5, 14 and 19, $9 \mu \mathrm{g}$. The location of the band due to the specific binding of NsrR is indicated.

\section{Figure 6. Kinetics of induction of the hcp-hcr and ogt promoters}

Cultures of strain JCB387 carrying pRW50 containing the hcp383-1 or ogt100 promoter fragments were grown anaerobically at $37^{\circ} \mathrm{C}$ in minimal medium. $20 \mathrm{mM}$ sodium nitrate was added when cells reached $\mathrm{OD}_{650}$ of $\sim 0.2$. $\beta$-galactosidase activities were measured immediately prior to the addition of sodium nitrate (timepoint 0 ) and at 3 minutes intervals following addition. The figure shows the ratio of the measured activity relative to timepoint 0 plotted as a function of time after the addition of sodium nitrate.

\section{Figure 7. Phylogenetic analysis of hcp-hcr operon regulatory region sequences}

The figure shows an alignment of the E. coli K-12 hcp-hcr operon promoter region sequence with corresponding sequences from related bacteria, downloaded from the XBASE database (xbase.bham.ac.uk)[29]. The different bacteria (and corresponding xbase Taxon ID) are: ECO, E. coli K12 (83333); SEN, Salmonella enterica subspecies enterica serovar Choleraesuis str. SC-B67 (321314); STY, Salmonella typhimurium LT2 (99287); YEN, Yersinia enterocolitica (393305); YPE, Yersinia pestis (229193); YPS, sequence from Yersinia pseudotuberculosis (349747). DNA targets for NarL (and NarP), FNR and NsrR are indicated by shaded horizontal inverted arrows. For each target, the consensus binding sequence is shown in bold, aligned with the actual sequence, and the centre of the site is noted. In the consensus sequences, $Y$ denotes either $C$ or $T, M$ denotes $A$ or $C, K$ denotes $G$ or $T$, $R$ denotes $A$ or $\mathrm{G}, \mathrm{W}$ denotes $\mathrm{A}$ or $\mathrm{T}$, and $\mathrm{N}$ denotes any base. The transcription start point in the $E$. coli $\mathrm{K}-12$ sequence is shown in lower case. Bases that are identical in each strain's genome are highlighted with black shading. 
Chismon et al. (2010) Figure 1
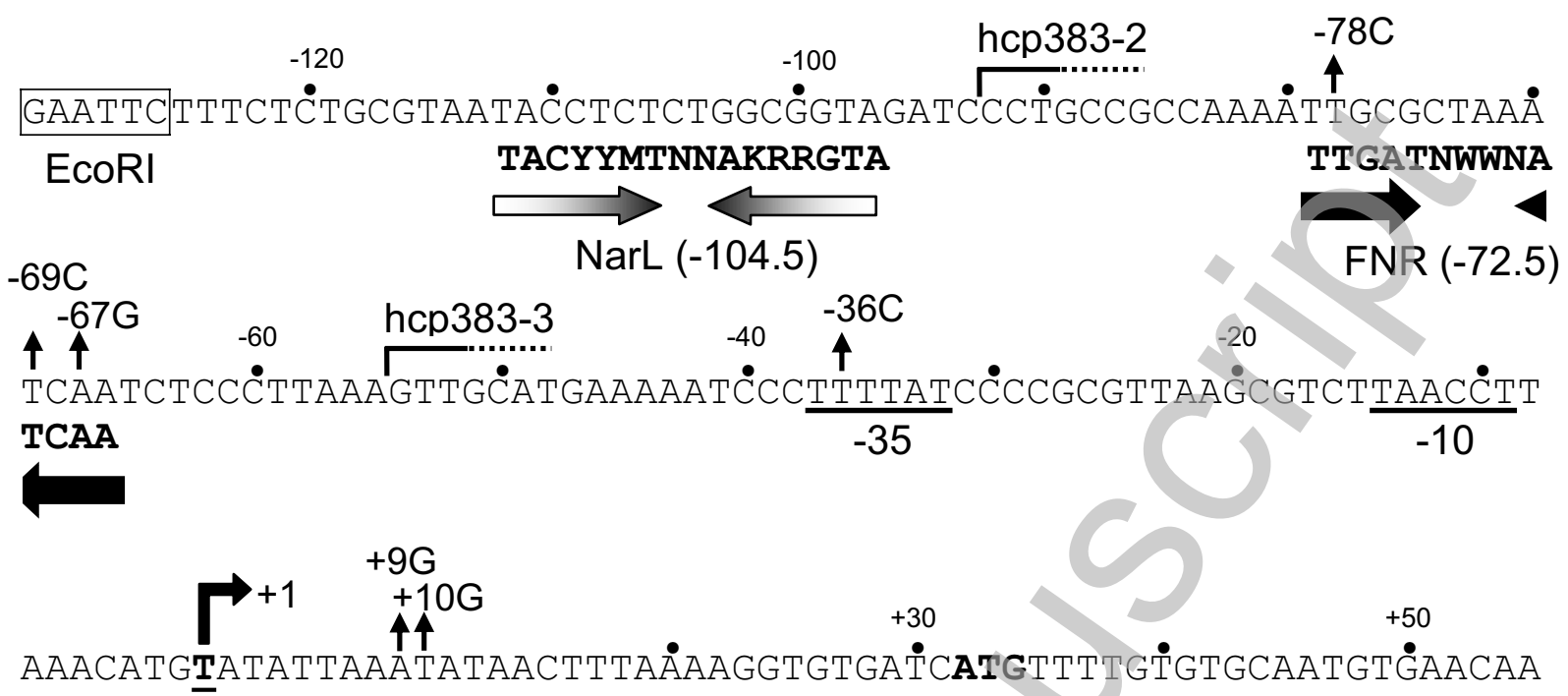

AANATGCATTTNAAATGCATNTT

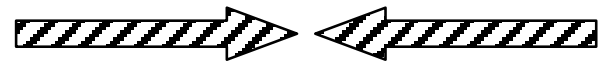

NsrR (+6)

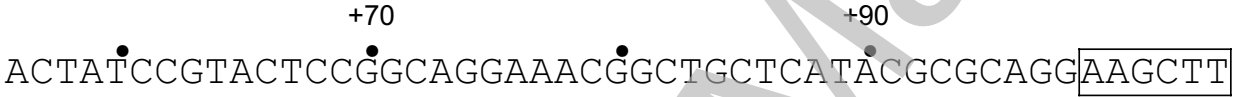

HindIII 
Chismon et al. (2010) Figure 2
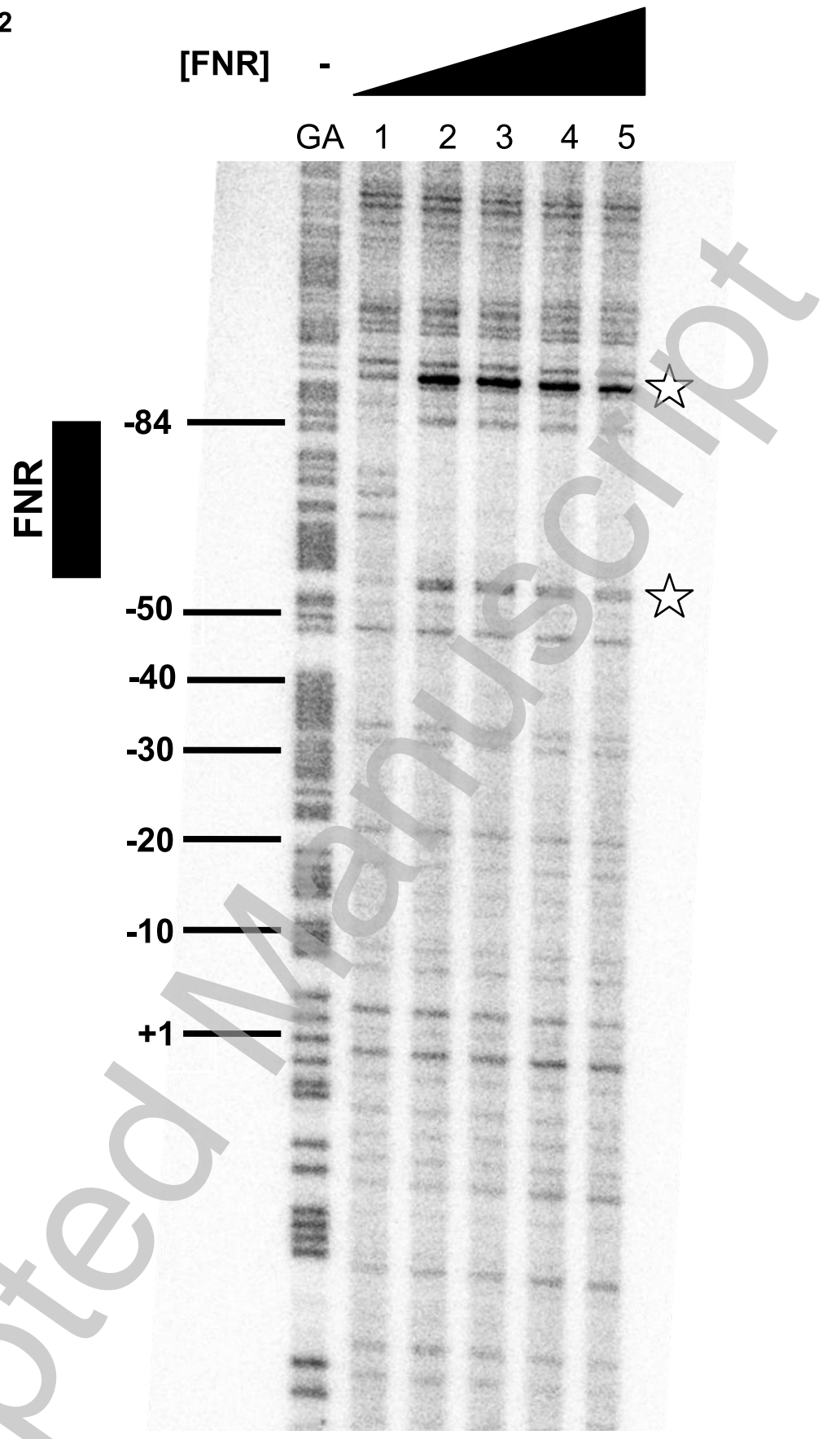
Chismon et al. (2010) Figure 3
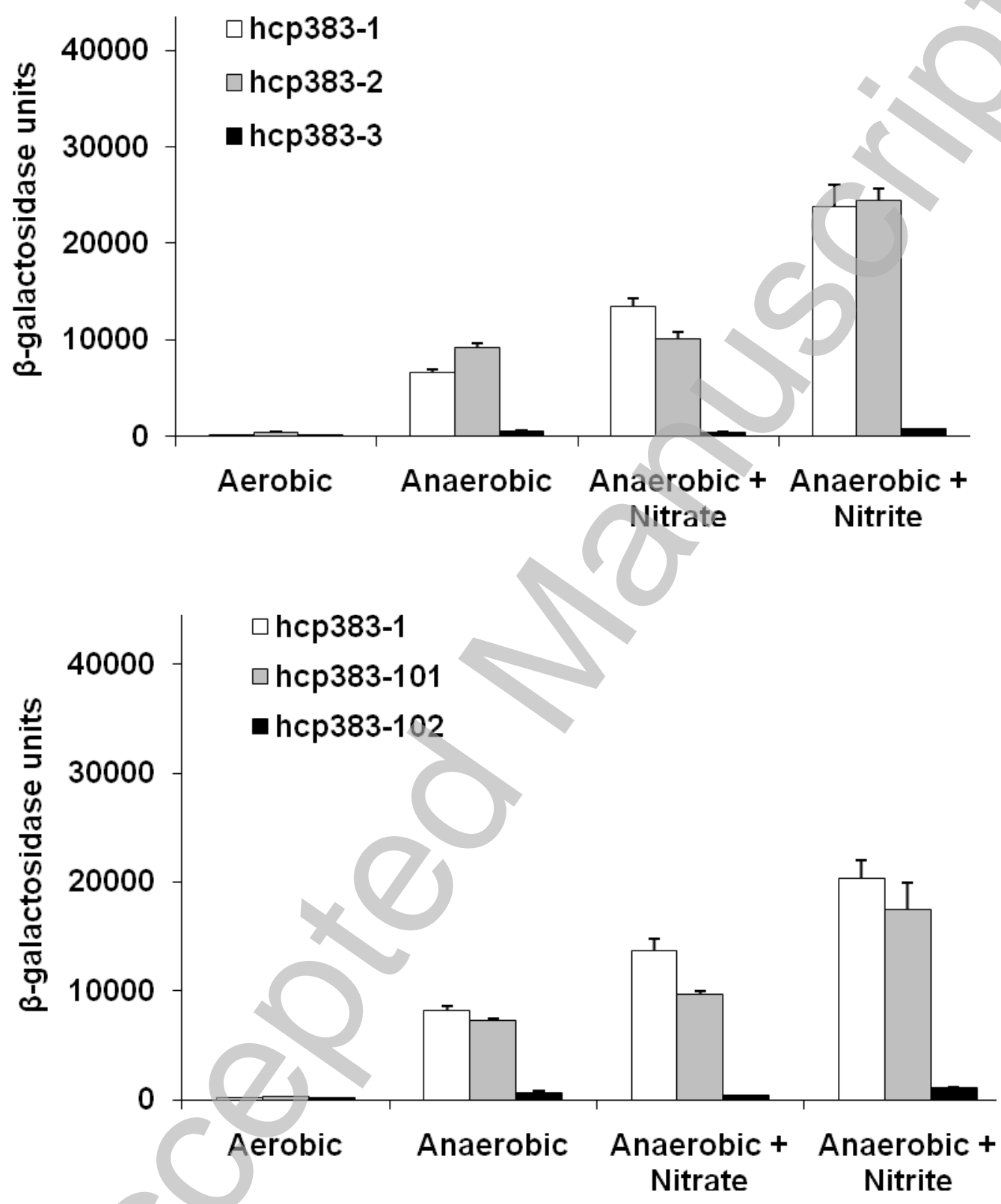
Chismon et al. (2010) Figure 4
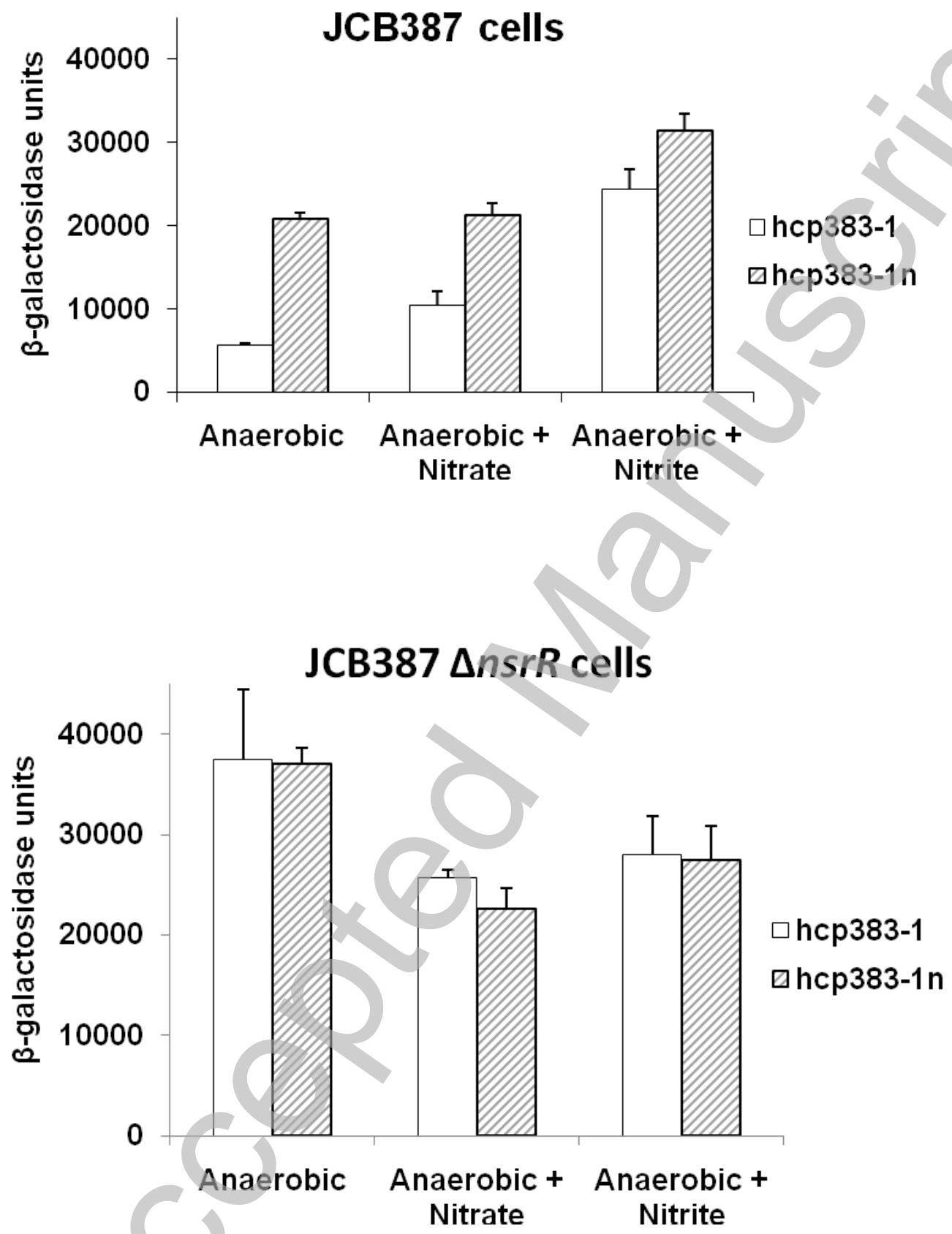
Chismon et al. (2010) Figure 5

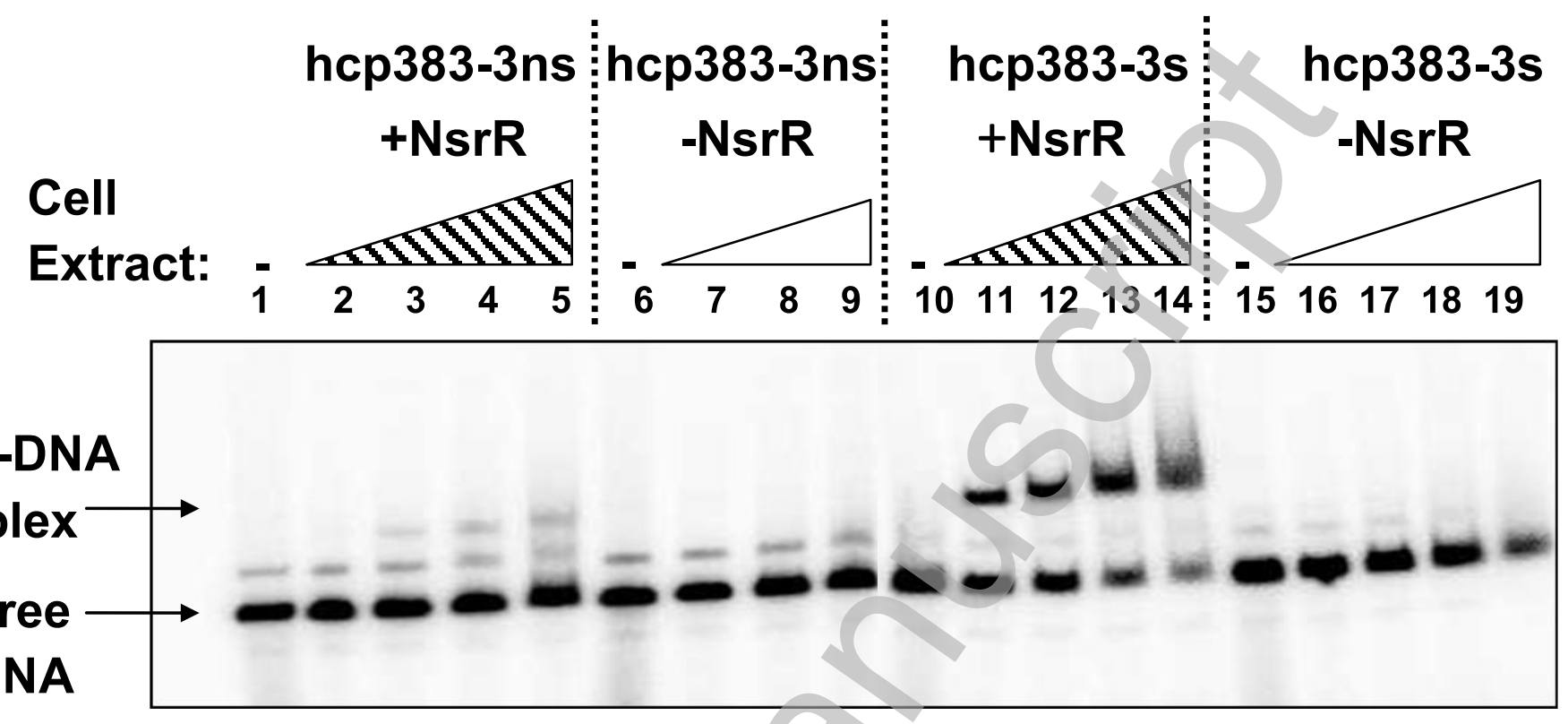


Chismon et al. (2010) Figure 6

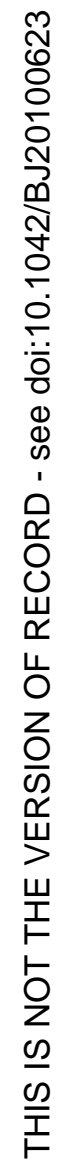

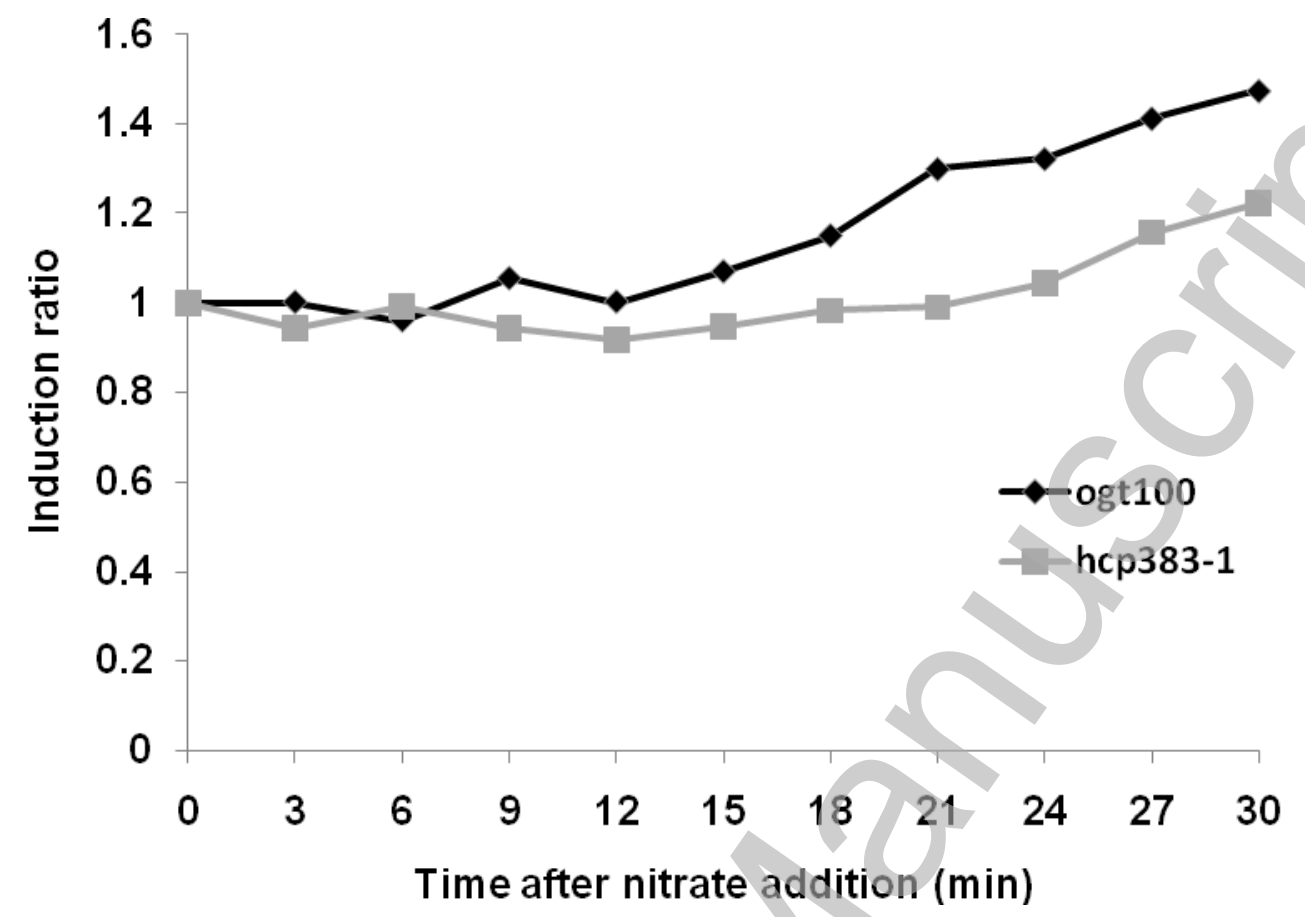

Licenced copy. Copying is not permitted, except with prior permission and as allowed by law. (C) 2010 The Authors Journal compilation (c) 2010 Portland Press Limited 
Biochemical Journal Immediate Publication. Published on 10 Jun 2010 as manuscript BJ20100623

Chismon et al. (2010) Figure 7

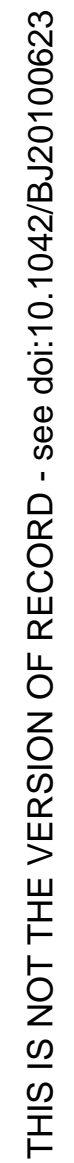
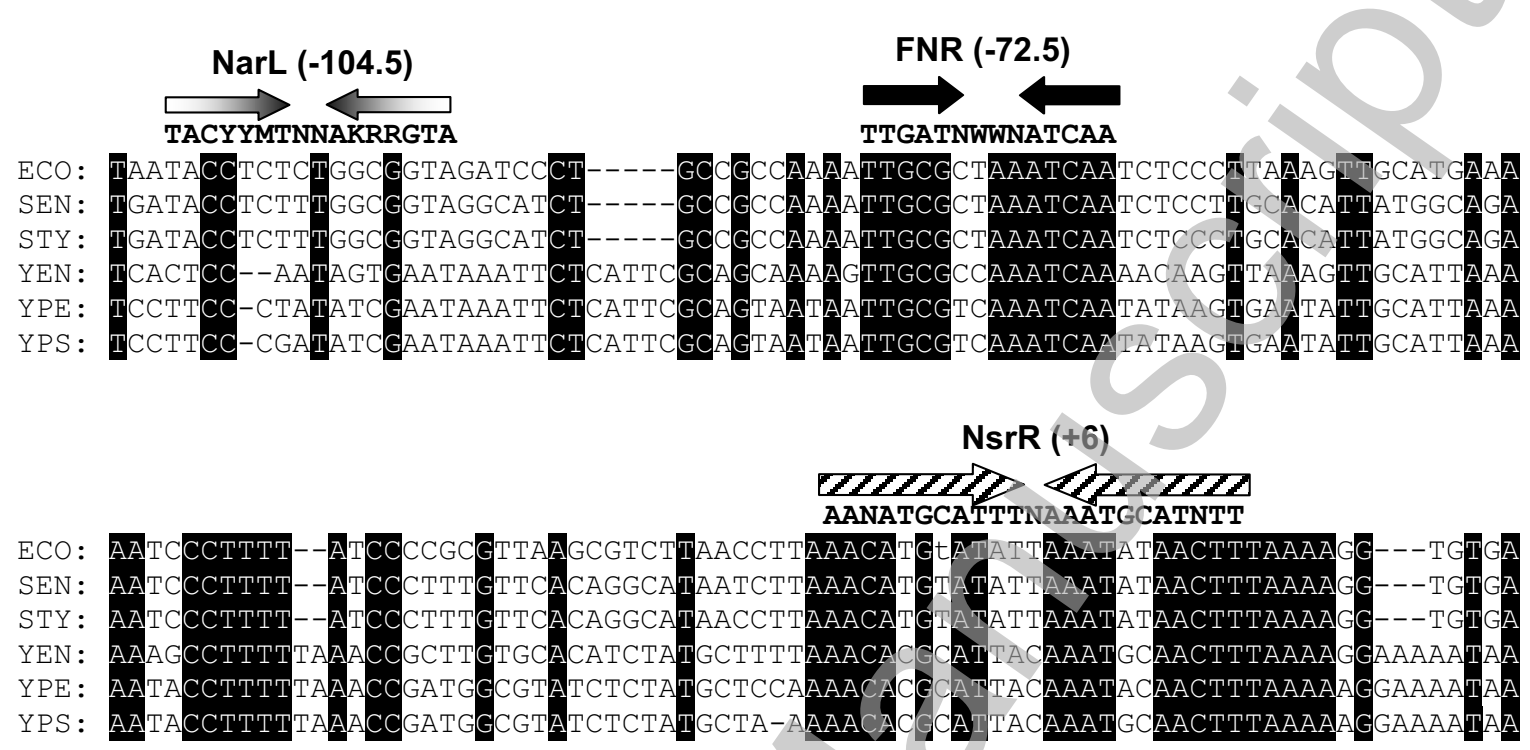

Licenced copy. Copying is not permitted, except with prior permission and as allowed by law. (C) 2010 The Authors Journal compilation (c) 2010 Portland Press Limited 